\title{
A FORMAÇÃO DOS PROFESSORES DOS ANOS INICIAIS QUE ENSINAM MATEMÁTICA
}

\author{
Fernando Antonio de Carvalho Cunha do Amaral $^{1}$ \\ José Alberto de Jesus ${ }^{2}$
}

\section{Resumo}

Este capítulo apresenta reflexões acerca da formação do professor dos anos iniciais com formação em Pedagogia que ensinam matemática, refletindo quais os saberes docentes e matemáticos este profissional precisa desenvolver para exercer com qualidade a sua função, entrelaçando as suas experiências já adquiridas. A metodologia aplicada foi a pesquisa bibliografia que possibilitou ao pesquisador manter um contato direto com o tema investigado. Conclui-se que existem professores que ensinam Matemática do mesmo modo como foram ensinados e alguns possuem resistência de realizar um trabalho em sala de aula que conduza o estudante a reflexão e não apenas a decorar fórmulas e mais fórmulas para serem aplicadas no dia da avaliação. Tudo isso são resultados das crenças que o professor construiu e até mesmo vivenciou quando estudantes na educação básica.

Palavras Chaves: Matemática. Professor. Formação. Saberes Docentes.

\begin{abstract}
This chapter presents reflections on the teacher's educational background of the initial years with academic formation in Pedagogy who teach mathematics, reflecting about the teaching skills and mathematical knowledge this professional needs to develop in order to fulfill his function with quality, intertwining his already acquired experiences. The applied methodology was the bibliographic research that allowed the researcher to maintain a direct contact with the investigated theme. It is concluded that there are teachers who teach mathematics in the same way as they were taught and some are resistant to carry out work in the classroom that leads the student to reflection and not just to memorize equations and more equations to be applied on the day of the test. All of these are the result of the beliefs that the teacher built and even experienced as a student in basic education.
\end{abstract}

Keywords: Mathematics. Teacher. Formation. Teaching Knowledge

\section{Introdução}

O Brasil adentrou o século XXI com o propósito de mudar o quadro educacional no qual se encontrava à época. Quase 20 anos depois, continua

\footnotetext{
${ }^{1}$ Doutorando em Ciências da Educação pela Faculdade Interamericana de Ciências Sociales-FICS. Mestre em Ciências da Educação pela Faculdade Interamericana de Ciências Sociales-FICS; Especialista em Coordenação Pedagógica e Gestão Escolar pela Faculdade Regional de Filosofia, Ciências e Letras de Candeias-FAC; Especialista em Gestão Educacional pela Faculdade Batista Brasileira; Especialista em Planejamento e Prática de Ensino Superior pela União Intermunicipal de Cursos Superiores da Bahia - UNIBA, em colaboração com as Faculdades Montenegro; Licenciado em Pedagogia pela Faculdade Social da Bahia; Licenciado em Matemática pela Universidade Federal de Santa Catarina em convênio com a Secretaria de Educação do Estado da Bahia; Bacharel em Ciências Contábeis pela Universidade Católica do Salvador- UCSal; Coordenador Pedagógico em São Francisco do Conde; Professor de Matemática do Colégio Estadual Martinho Salles Brasil- São Francisco do Conde-Ba. E-mail: nando1572@gmail.com

2 Doutorando em Ciências da Educação pela Faculdade Interamericana de Ciências Sociales-FICS. Mestre em Ciências da Educação pela Faculdade Interamericana de Ciências Sociales-FICS. Especialista em Metodologia do Ensino Superior pela Faculdade de Educação da Bahia. Licenciatura em Eletricidade pela Universidade do Estado da Bahia - UNEB. Licenciatura em Matemática pela Universidade Salvador- UNIFACS. Professor da Rede Estadual do Estado da Bahia - Salvador. Email: dahorajesus2000@yahoo.com
} 
buscando alternativas que possibilitem uma melhoria significativa nos índices da educação básica que apesar de algumas poucas melhorias, continuam aquém dos ideais propostos nos documentos oficiais.

Desta forma, voltou-se o olhar para a questão formativa do professor seja inicial, seja continuada, como uma alternativa que se tornasse eficaz para a mudança no cenário que tanto se deseja, para tanto, algumas providências foram tomadas, como a criação das diretrizes para o Curso de Licenciatura em Pedagogia, efetivação dos artigos da Lei de Diretrizes e Bases da Educação Nacional-LDBN como já abordamos no capítulo anterior, no trato dos artigos efetivos sobre formação, bem como, dos inúmeros cursos e encontros formativos oferecidos pelo Ministério da Educação e Cultura- MEC, as Secretarias Estaduais e Municipais de Educação. Para prosseguirmos nossas reflexões sobre os professores polivalentes, tomamos as ideias de que:

Para ser professor é necessário mais que vocação, predisposição,
predestinação. Muitas pessoas "caem" na profissão por força das
circunstâncias. Nos cursos de graduação que possuem as linhas de
Bacharelado e Licenciatura na mesma área costumam aparecer casos de
alunos que concluem o Bacharelado e depois cursam a Licenciatura e se
justificam dizendo que é mais fácil conseguir um emprego assim. Sempre
há vagas no mercado para professores e dificilmente ficarão
desempregados (RIBEIRO, 2007, p.18).

Faz-se necessário que o futuro professor seja preparado para exercer seu papel com responsabilidade e competência. Por essas e outras questões é que o desenvolvimento de pesquisas e publicações de professores vem crescendo nos últimos anos. Preocupações relacionadas com a formação profissional do professor e o delineamento das atribuições e necessidades formativas deste profissional são constantes nesses estudos e trabalhos de Phillipe Perrenoud.

Esta preocupação estende-se a partir da formação inicial, que conduz nossas reflexões e percebermos que urge a necessidade de políticas públicas voltadas para preencher as lacunas, que cada vez maiores, parecem sobrepor-se às iniciativas e propostas para o assunto em questão, que não envolvem apenas a formação dos professores, mas sim outros elementos que supostamente são esquecidos pelas autoridades competentes, como, por exemplo, a falta de valorização deste profissional, infraestrutura adequada. 


\section{Formação Inicial}

A formação inicial de acordo com está relacionada com a aprendizagem adquirida, na Universidade durante o curso, com a vivência teórica e prática que são próprias à formação profissional e complementadas pelos estágios (LIBÂNEO, 2004).

Quanto aos estágios estes são obrigatórios na formação inicial do pedagogo quando ainda encontra-se na Universidade preparando-se para exercer a profissão, e também desempenha papel necessário e importante para o exercício do futuro professor ao passo que permite ao estudante conhecer o campo profissional, viver situações específicas, vivenciar o dia-a-dia na prática a sala de aula. Neste espaço são trabalhados conhecimentos necessários referindo-se ao estágio, inferindo sobre a formação inicial ao tratar do estágio, pois:

O campo de conhecimentos e eixo curricular central nos cursos de formação de professores possibilita que sejam trabalhados aspectos indispensáveis à construção da identidade, dos saberes e das posturas específicas ao exercício docente (PIMENTA e LIMA, 2012, p.61).

Ainda sobre as informações, acima se pode acrescentar que:

Os aspectos elencados pelas autoras definem a identidade profissional, necessário ao exercício da docência. Através da experiência de Estágio, o pedagogo em formação tem a oportunidade de dialogar com tais aspectos, confrontando suas crenças com a realidade que ora se apresenta (COSTA, 2011, p.54).

O Estágio com suas peculiaridades tornam-se prioridade para a formação inicial dentro de uma perspectiva reflexiva, delineando um fazer docente em função das possibilidades de desenvolvimento.

\section{Formação Continuada}

Ao pensar sobre o seu fazer em sala de aula deve conduzi-lo a tomada de decisões, pois educação é uma área complexa, e precisa constantemente de aperfeiçoamento, que o professor esteja exercitando a elucubração. Vale lembrar que:

O professor constitui-se num "agente reflexivo de sua prática pedagógica, e passa a buscar subsídios teóricos e metodológicos, que o ajudem a compreender e solucionar problemas e desafios do seu trabalho.. A reflexão assim é praticada pelo professor no trabalho diário, valendo-se das contribuições teóricas que the permite a ultrapassar interpretações e soluções baseadas apenas no senso comum (OLIVEIRA, 2014, p. 65). 
As instituições ganham muita responsabilidade ao se tratar da formação continuada ou em serviço forma utilizada por alguns autores, sendo assim a sua obrigação assegura as condições para que haja um verdadeiro e construtivo momento formacional, uma vez que:

\begin{abstract}
A formação em serviço ganha hoje tamanha relevância que constitui parte das condições de trabalho profissional. Os sistemas de ensino e as escola precisam assegurar condições institucionais, técnicas e materiais para o desenvolvimento profissional permanente do professor. Especialmente, é imprescindível assegurar aos professores horas remuneradas para realização de reuniões semanais, seminários de estudo e reflexões coletivas, onde possam compartilhar e refletir, sobre a prática com colegas, apresentar seu trabalho publicamente (contar como trabalham, o que funciona, as dificuldades, etc), reunir-se com os pais e outros membros da comunidade, participar da elaboração do projeto pedagógico-curricular (LIBÂNEO, 2004, p,130).
\end{abstract}

$\mathrm{Na}$ verdade o autor apresenta as condições necessárias para que aconteçam as formações continuadas, mas infelizmente, muitas vezes constatamos na realidade inversa, as formações são deixadas em segundo plano.

O professor não pode omitir-se de que o processo formativo é de suma importância para o bom exercício da profissão, por isso, é que não pode esquecer de vários aspectos como os epistemológicos, cognitivos inerentes ao ato de ensinar. No contexto da formação continuada apresenta-se um pensamento contrário ao abordado referente à formação continuada, no sentido de valorizar-se mais os 'pacotes' do que a valorização do profissional, ao abordar que:

Percebe-se como uma tal prática transfira autoritarismo. De um lado, nenhum respeito à capacidade crítica dos professores, a seu conhecimento, à sua prática; de outro na arrogância com que meia dúzia de especialistas que se julgam iluminados elabora ou produz o 'pacote' a ser docilmente seguido pelos professores que, para fazê-lo, devem recorrer aos guias (FREIRE, 2001,p,71).

$\mathrm{Na}$ verdade a crítica que Freire faz refere-se ao fato de que no processo formativo, os responsáveis pela formação "compram" pacotes, como as autoridades dominam e não concedem ao professor crítica, reflexão, contribuição, não há espaço para que o professor possa expressar-se e simplesmente como que um 'livro de receitas' para um determinado problema, é o que muitas vezes acontece, é só o professor pegá-lo, encontrar o que fazer e parece que tudo esta normal, enquanto na verdade ocorreu apenas mais um silenciamento do professor. Porém, para que estas formações obtenham sucesso, pode-se sugerir os seguintes princípios,:

O adulto em formação é portador de uma história de vida [...] mais importante do que em formar_este adulto é tentar refletir sobre o modo como 
ele se forma; a formação é sempre um fenômeno de cunho individual, na tríplice dimensão do saber (conhecimentos), saber-fazer (capacidades) e saber-fazer (atitudes); e formar não é ensinar às pessoas determinados conteúdos, mas sim trabalhar coletivamente em torno da resolução de problemas. a formação faz-se na 'produção' e não no 'consumo' do saber (NÓVOA, 1988, p.p. 128 e 129).

A questão formacional iniciada ou continuada provoca debates e discussões entre os teóricos que se debruçam sobre o assunto., percebemos que, o que falta é escutar quem vive o "chão da sala de aula", que está lá cotidianamente e mais do que ninguém sabe das necessidades tanto suas quanto dos alunos. Precisa resolver determinados conflitos, que tem a responsabilidade de formar cidadãos responsáveis, críticos, capazes de se posicionarem frente a um determinado fato com o que se almeja a autonomia.

Concorda-se que a questão formativa no Brasil para que alcance níveis satisfatórios, superando as reciclagens e capacitações, ainda é um cenário a construir, porque precisa-se olhar para o profissional como agente de seu protagonismo (CASTRO e AMORIM, 2015).Ao delinear uma formação dos professores de Matemática aborda-se esta questão, pois:

\begin{abstract}
Fica claro que esses cursos de Licenciatura de Matemática estão formando profissionais com perfis diferentes, alguns com uma formação Matemática profunda, que talvez não se sintam preparados para enfrentar as situações de sala de aula, que não se restringem ao se restringem ao saber matemática. Outros, com uma formação .pedagógica desconexa da formação específica em matemática, forçando o licenciado a encontrar as inter-relações entre essas formações. Considera-se que os poucos cursos de Licenciatura em Matemática que oferecem uma formação mais aprofundada em Educação Matemática, como os que estariam propiciando experiências, aos futuros professores, mais contextualizadas e significativas para a construção da prática pedagógica (GATTI e NUNES,2009, p.109)
\end{abstract}

Percebe-se assim, que ao propor formação para os professores é preciso pelo levar em consideração o currículo que nem sempre atende de maneira satisfatória uma vez, que no nosso entendimento currículo se refere a toda experiência pelo aluno durante a sua caminhada estudantil.

\title{
Saberes Docentes e Saberes Matemáticos
}

Saberes constituem-se num conjunto de conhecimentos construídos a partir das diversas experiências em diversas situações que permitem ao ser humano desenvolver as diversas atividades cotidianas. Parece-nos, portanto, que este entendimento aplica-se também à prática docente e também especificamente a 
Matemática, ciência que é o fio condutor da nossa pesquisa. Cabe fazer referência aos docentes aos quais recorremos a exposição de que:

[...] o saber é sempre o saber de alguém que trabalha alguma coisa no intuito de realizar um objetivo qualquer. Além disso, o saber não é uma coisa que flutua no espaço: o saber dos professores é o saber deles que está relacionado com a pessoa e a identidade deles, com sua experiência de vida e com a sua história profissional, com as suas relações com os alunos em sala de aula e com os outros autores escolares na escola (TARDIF, 2014,11).

Os saberes dos professores estão relacionados com as mediações inerentes ao trabalho docente em sala de aula, espaço composto por situações heterogêneas e são essas situações que fornecem ao professor condições necessárias para o enfrentamento dessas e outras situações que acontecem no dia-a-dia dentro deste espaço.

E ai cabe ao professor analisar e interpretar, lembrando que cada pessoa possui uma história de vida, história profissional, dentre outros diferentes aspectos. Pois os conhecimentos profissionais do professor relacionados com as suas práticas sociais, seja na própria escola, cultura pessoal, experiências com outros colegas, na família são construídos durante a vida, no exercício da profissão. Baseando-se nesta realidade e na articulação entre eles, ou seja, de um conjunto de conhecimentos, pode-se afirmar que são:

\begin{abstract}
Saberes oriundo da formação profissional, ou seja, aqueles conhecimentos transmitidos pelas instituições de formação de professores destinados a contribuir com a formação de uma ideologia pedagógica e inserem-se no campo das Ciências da Educação; Saberes disciplinares, os quais correspondem aos diversos campos do conhecimento (Matemática, Biologia, História, Literatura, etc.) e emergem da tradição cultural. São transmitidos nos cursos e departamentos universitários independente das faculdades de educação e dos cursos de formação de professores; Saberes curriculares, os quais se apresentam concretamente sob a forma de programas escolares (objetivos, conteúdos, métodos) que os professores devem aprender a aplicar; Saberes experiências, desenvolvidos no trabalho cotidiano sob a forma de habilidades, de saber- fazer e saber- ser ( TARDIF, Ibid, p.3)
\end{abstract}

No que concerne aos estudos e pesquisas sobre os professores que ensinam matemática varias pesquisas são realizadas voltadas tanto para formação, quanto para as praticas dos professores, voltadas para a reflexão. São citados pelos autores do artigo, as pesquisas desenvolvidas por Fiorentini e Nacarato, onde são apresentados por Fiorentini (1993) quatro eixos por ele concebidos como fundantes 
ao professor que ensina Matemática, vale destacar que estes eixos encontram-se na obra citada, sendo eles:

\begin{abstract}
a) Formação matemática acadêmica e escolar, relativa a disciplina, tanto em seus aspectos procedimentais e sintáticos quanto conceituais, semânticos e atitudinais; b) Formação geral: cultura geral, educação humanística, educação tecnológica;c) Formação cientifico- pedagógico: fundamentos históricos, sociológicos, filosóficos, psicológicos, epistemológicos relativos às ciências da educação;d) Formação relativa à atividade profissional da docência: Sabres da atividade profissional relativa ao ensino e a aprendizagem da matemática - saberes curriculares complexos relativos à experiência ou ao trabalho docente nos diferentes contextos, incluindo também o saber fazer e o saber ser. Um desses contextos é o universitário relativo ao trabalho docente dos professores da licenciatura em matemática em fazer a sua tarefa de formar professores de matemática (FIORENTINI,1993 apud GONÇALVES E FIORENTINI, 2005, p.73-74).
\end{abstract}

Percebe-se que esses saberes embora estejam mais próximos do professor que lecionará, em alguns saberes encaixados para os anos iniciais, notando-se que várias vezes o autor cita a palavra formação. Devemos destacar que o eixo principal dessa formação é aquele relativo à atividade profissional, uma vez que o professor precisa ser criativo, ter conhecimentos de teorias e práticas que são primordiais no ato de ensinar assim como daqueles saberes e fazeres teóricos e didáticos.

Aos abordar os saberes docentes outros elementos vêm a mente, por considerar que são importantes para que o professor consiga trabalhar com a disciplina matemática, que é a metodologia, e a esse respeito destaca-se que:

Os professores que adotam em suas praticas pedagógicas, novas metodologias de ensino e consideram aquilo que o aluno traz como conhecimento do seu cotidiano, tem proporcionado aulas mais dinâmicas e participativas. Contudo, não podemos deixar de lado, que a formação continuada, é fundamental na constituição da idade do professor. Portanto a formação deve ser proporcionada pela escola ou secretarias. Uma formação que busque pensar e reconstruir praticas pedagógicas, que desafie paradigmas e que busque um novo caminhar para o ensino e para aprendizagem, é tarefa decisiva na formação docente e discente (MONTIBEUER, 2015, p.28).

Apesar de a autora citar também a formação, já que trazemos nossas reflexões no capitulo anterior, ela aborda por causa do nosso entendimento da metodologia que fator imprescindível no processo de ensino e de aprendizagem é ai que os saberes docente entrelaçasse com a experiência à medida que o professor faz esse entrelaçamento, porque coloca os seus saberes docente com as suas experiências pessoais e seus saberes matemáticos pensam como esses aportes estão um colaborando com o outro. 


\section{Considerações Finais}

Ao pensar na questão formativa do professor deve-se pensar na escola que temos, com todas as suas dificuldades e a que queremos, sem contanto considerar as transformações que socialmente ela vem passando, considerando a educação como um direito social estabelecido pelos documentos oficiais. Não devemos considerar que só na pessoa com uma formação aquém das suas necessidades irá solucionar todos os problemas da educação, mas é preciso unir esforços, estabelecer parcerias com Unidades.

Discutir, portanto, numa formação matemática para o professor é preciso considerar as suas reais necessidades que em muitos casos são lacunas deixadas na formação inicial que não conduz aos estudos das teorias ou só se fica preso a estes estudos, mas oferecer também situações práticas as quais podem ser trabalhadas em salas com os alunos.

As experiências são vivenciadas originarias de diversas situações diferentes, em lugares diferentes, e assim nesta troca professor vai buscar os conhecimentos que mais se encontram com os seus saberes e com as experiências. Percebe-se assim, que saberes e experiências caminham juntos no processo de ensino e de aprendizagem, constituídos assim praticas que vão sendo agregadas ao fazer pedagógico e utilizadas sempre que houverem necessidade.

Ainda sobre os saberes matemáticos que se bem trabalhados colaboram para que a matemática seja trabalhada constituindo-se numa ferramenta capaz de que o aluno passe a enxergá-la com outros olhos, como necessárias para resolver situações cotidianas, e a veja como mais um instrumento que possibilite a construção da cidadania.

Parece estar claro que a constituição profissional dos professores que ensinam mediam processos de aprendizagem matemática perpassada por vivências, percursos escolares e profissionalizantes, meios sociais e, sobretudo, por um mapa de relações intersubjetivas que agrega saberes disciplinares, curriculares, experienciais, científicos, pedagógicos e de aprendizagem matemática.

\section{Referências}

CASTRO, M.M.C.; AMORIM, R.M.A. A Formação Inicial e a Continuada: diferenças conceituais que legitimam um espaço de formação permanente de vida. Cad. CEDES [online]. 2015 
COSTA, S.C.S. O professor que ensina matemática nos anos iniciais do ensino fundamental: limites e possibilidades do curso de licenciatura em Pedagogia. Dissertação de Mestrado (Educação e Ciências). Universidade Cruzeiro do Sul. SP,2011.

GONÇALVES, T.; FIORENTINI, D. Formação e desenvolvimento profissional de docentes que formam matematicamente futuros professores. In: FIORENTINI, D.; NACARATO, A. (Org.). Cultura, formação e desenvolvimento profissional de professores que ensinam matemática: investigando e teorizando a partir da prática. São Paulo: Musa Editora; Campinas, 2005.

FREIRE, P. Pedagogia da autonomia: saberes necessários à prática docente. São Paulo: Paz e Terra, 90, 2001

GATTITI, B.A; NUNES, M.M.. Formação de professores para o ensino fundamental: estudo de currículos das licenciaturas em Pedagogia, Língua Portuguesa, Matemática e Ciências Biológicas. São Paulo: FCC/DPE,2009.

LIBÂNEO, J.C. Organização e gestão da escola: teoria e pratica. 5 ed. Goiânia: Editora Alternativa, 2004.

MONTIBELLER, C. Questão social e serviço social. Indaial: Grupo UNIASSELVI, 2015.

NÓVOA, A. A formação tem que passar por aqui: as histórias de vida no projeto PROSAULAS. In: NÓVOA, A.; FINGER, M. (org). 0 método autobiográfico e a formação. Lisboa: Ministério da Saúde, 1988

OLIVEIRA, M.A.P. Análise de uma experiência de formação continuada com professores dos anos iniciais do ensino fundamental. 2014

PIMENTA, S.G.; LIMA, M.S. Estágio e Docência. 7 ed. São Paulo: Cortez,2012.

RIBEIRO, A.E. Internet \& Ensino Novos Gêneros: Outros Desafios In ARAUJO, Julio César (Org.)-KD o Professor? Tb foi Navegar? Rio de Janeiro - RJ : Lucerna 2007.

TARDIF, M. Saberes docentes e formação profissional. Petrópolis: Vozes, 2014 